\title{
Copper (11) lons Biosorption from Aqueous Solution Using Modified Moringa Oleiferal Leaves (MMOL)
}

\author{
Adebayo Oluwafemi Lawrence*, Kenni Amoke Monisola, Oyetunde Julius Gbenga, \\ Jegede Rufus Oluwafemi, Ajayi Margret Grace
}

Department of Chemistry, College of Education, Ikere, Ekiti State, Nigeria

Email address:

femtay41@yahoo.co.uk (A. O. Lawrence)

${ }^{*}$ Corresponding author

\section{To cite this article:}

Adebayo Oluwafemi Lawrence, Kenni Amoke Monisola, Oyetunde Julius Gbenga, Jegede Rufus Oluwafemi, Ajayi Margret Grace. Copper (11) Ions Biosorption from Aqueous Solution Using Modified Moringa Oleiferal Leaves (MMOL). American Journal of Physical Chemistry. Vol. 7, No. 2, 2018, pp. 12-18. doi: 10.11648/j.ajpc.20180702.11

Received: February 11, 2018; Accepted: March 14, 2018; Published: June 1, 2018

\begin{abstract}
The present research work demonstrated the ability of MMOL in removing Copper (II) ions from an aqueous solution. The modified (MMOL) and unmodified moringaoleifera (UMOL) was characterized based on PZC and surface area. Isotherm experiments were conducted and the data obtained were fitted to Langmuir and Freundlich isotherm equations. The Freundlich equation gave the best description of the sorption process and the maximum saturated monolayer sorption capacity of the MMOL for CU (II) ions was $78.45 \mathrm{mg} \mathrm{g}^{-1}$. The kinetics of the sorption process was studied by varying the initial CU (II) ions concentrations and the result obtained was analyzed by using pseudo-first-order and pseudo-second-order kinetic models. The pseudo second-order kinetic model was found to fit the experimental data for the entire sorption period with high coefficient of determination $\left(\mathrm{r}^{2}\right)$. The effects of MMOL dose were studied using batch sorption system. The linear form of the Langmuir equation was used to analyze the data obtained when the sorbent dosage was optimized by method of continuous variation. The results obtained showed that the equilibrium monolayer sorption capacity, $\mathrm{q}_{\mathrm{m}}$, of the MMOL for CU (II) ions decreased (78.45 - $\left.38.66 \mathrm{mg} \mathrm{g}^{-1}\right)$ with an increase in sorbent dosage. The result obtained from $\mathrm{pH}$ optimization showed that $\mathrm{CU}(\mathrm{II})$ ions removal increases with increase in $\mathrm{CU}(\mathrm{II})$ ions solution $\mathrm{pH}$.
\end{abstract}

Keywords: Biosorption, Kinetics, Modified Moringaoleifera Leaves, Pseudo First Order, Pseudo Second Order

\section{Introduction}

Water pollution containing heavy metal ions such as chromium, cadmium, copper, lead, nickel, mercury and zinc from industrial and domestic wastes is becoming one of the most serious environmental problems worldwide [1]. Because of the low concentration of heavy metals in various resources it can be more harmful to the environment and adversely affecting the human health. The remedy of heavy metals is so significant because of the continuance in the environment. Industrial wastewater treatment covers the mechanisms and processes used to treat wastewater that is produced as a by-product of industrial or commercial activities. After treatment, the treated industrial wastewater (or effluent) may be reused or released to a sanitary sewer or to a surface water in the environment. Most industries produce some wastewater although recent trends in the developed world have been to minimize such production or recycle such wastewater within the production process. However, many industries remain dependent on processes that produce wastewaters. Copper pollution generally arises from copper mining and smelting, brass manufacturing, electroplating industries and excessive use of $\mathrm{Cu}$-based agrochemicals. In fact, copper is essential to human life and health, but like all other heavy metals, it is potentially toxic at high concentrations. The excessive amounts of $\mathrm{Cu}$ (II) in fresh water resources and aquatic ecosystem damage the osmoregulatory mechanism of the freshwater animals and cause mutagenesis in humans [2]. Large quantities of copper are released to the environment by discarding industrial waste without further treatment [3]. According to World Health Organization (WHO) the permissible limit of $\mathrm{Cu}$ (II) in water is $1.5 \mathrm{mg} / 1$ [2]. The most commonly used methods 
for the removal of metal ions from industrial effluents include: chemical precipitation, solvent extraction, oxidation, reduction, dialysis/electrodialysis, electrolytic extraction, reverse osmosis, ion-exchange, evaporation, cementation, dilution, adsorption, filtration, flotation, air stripping, steam stripping, flocculation, sedimentation, soil flushing/washing chelation, etc. Among these, adsorption has evolved as the front line of defense and especially for those, which cannot be removed by other techniques [4]. Additionally, these methods may also affect the generation of secondary wastes, which are difficult to treat. Adsorption is an alternative technology in which increased amount of study has been focused because of cost effectiveness, local availability and technical feasibility for the removal of heavy metal ions form the wastewater [5]. Adsorption of molecules can be represented as a chemical reaction:

$$
\mathrm{A}+\mathrm{B} \Leftrightarrow \mathrm{A} . \mathrm{B}
$$

Where $A$ is the adsorbate, $B$ is the adsorbent, and $A$. $B$ is the adsorbed compound. Adsorbates are held on the surface by various types of chemical forces such as hydrogen bonds, dipole-dipole interactions, and van der Waals forces. If the reaction is reversible, as it is for many compounds adsorbed to activated carbon, molecules continue to accumulate on the surface until the rate of the forward reaction (adsorption) equals the rate of the reverse reaction (desorption). When this condition exists, equilibrium has been reached and no further accumulation will occur. Isotherm adsorption models have been used in waste stream treatment to predict the ability of a certain adsorbent to remove a pollutant down to a specific discharge value. When a mass of adsorbent and a waste stream are in contact for a sufficiently long time, equilibrium between the amount of pollutant adsorbed and the amount remaining in solution will develop. For any system under equilibrium conditions, the amount of material adsorbed onto the media can be calculated using the mass balance of Equation below:

$$
q_{e}=\mathrm{Vx} \frac{C_{o}-C_{e}}{M_{s}}
$$

where $\mathrm{C}_{0}$ and $\mathrm{C}_{\mathrm{e}}(\mathrm{mg} / \mathrm{L})$ are the initial and the final concentrations of adsorbates in flasks, respectively, $\mathrm{V}$ is the volume of the solution (in Litres) and $m$ is the mass of dry adsorbent used in grammes [6]. Adsorption isotherms are important criteria in optimizing the use of adsorbents as they describe the nature of interaction between adsorbate and adsorbent. Thus, analysis of experimentally obtained equilibrium data by either theoretical or empirical equations is useful for practical design and operation of adsorption systems. The Langmuir and Freundlich adsorption isotherms were applied to each metal under study.

Moringaoleifera is a multipurpose tree with most of its parts being useful for a number of applications (Figure 1). It is generally used in a number of developing countries as a vegetable, medical plant and a source of vegetable oil. It has an impressive range of medicinal uses with high nutritional value [7]. On the other hand, Moringaoleiferaseeds have been found to be a natural coagulant, flocculants, softener, disinfectant, and sludge conditioner[8-10], heavy metal remover in water and wastewater treatment [11-13].

In this study MMOL (biosorbent) is used for CU (II) ions removal from water as a natural alternative for synthetic sorbents. Synthetic water was used to find optimum conditions for water treatment using biosorbent. The effect of biosorbent $\mathrm{pH}$, dosage and time were studied.

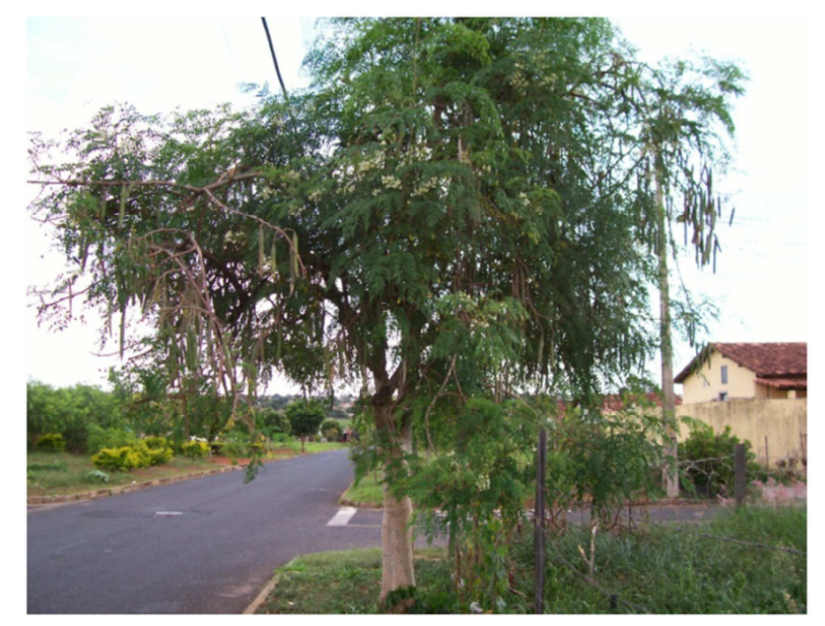

Figure 1. Moringaoleifera tree.

\section{Materials and Methods}

\subsection{Synthetic Effluents Preparation}

An accurate weight of $1.000 \mathrm{~g}( \pm 0.0005) \mathrm{CuSO}_{4}$ was dissolved in 1 litre of distilled water to produce the stock solutions of synthetic effluent. These stock solutions were then diluted into the required concentrations using distilled water whenever necessary. Every time the stock and standard solution have been prepared, the solution was shaken for about 2 hours using orbital incubator shaker at $30^{\circ} \mathrm{C}$ and $100 \mathrm{rpm}$ to ensure that each solution was homogeneous.

\subsection{SorbentsPreparation and Characterization}

The moringaoleifera leaves (MOL) were removed from the plant and were dried for about 2 weeks. When satisfactorily dried, the leaves were grounded to powder using a mechanical grinder. $80 \mathrm{~g}$ of the biosorbent was treated with $1600 \mathrm{ml}, 0.1 \mathrm{M} \mathrm{HNO}_{3}$ with continuous stirring for 2 hours to remove metals from the biosorbent and increase its surface area. Then it was washed with $500 \mathrm{ml}$ distilled water, this was done in thrice and the sample was then sun dried for about 6 hours. After the acid treatment, the adsorbent (about 50g) was extracted with $400 \mathrm{ml}$ methanol to remove inorganic and organic matter from the sorbent surface. This was carried out for 2 hours 30 minutes. The adsorbent $\mathrm{pH}$ was adjusted to 7 using $0.1 \mathrm{M} \mathrm{NaOH}$, washed with distilled water, oven - dried for about 1 hour, kept in an air - tight plastic container and put in a refrigerator at $4^{\circ} \mathrm{C}$ prior the analysis. The MMOL and unmodified moringaoleifera leaves (UMOL) samples were characterized thus: specific surface area was determined 
using the method of Sear's, [14], the point zero charge (PZC) was determined by solid addition method [15].

\subsection{Adsorption Studies}

The sorption capacity of the MMOL was evaluated via equilibrium isotherm analysis. The sorption capacities was determined by contacting $50 \mathrm{~mL}$ solution of known concentration of CU (II)that ranged between 25 and 300 $\mathrm{mg} / \mathrm{L}$ with $0.2 \mathrm{~g}$ of the adsorbent (MMOL). The mixture was stirred at $200 \mathrm{rpm}$ in thermostatic shaker for $2 \mathrm{~h}$, samples were removed, centrifuged, and the supernatant was analyzed for residual $\mathrm{CU}$ (II) concentration by using a flame atomic absorption spectrophotometer. The amount of CU (II) sorbed per unit mass of the adsorbent (in $\mathrm{mg} / \mathrm{g}$ ) was calculated using equation 1.

The sorption process variables were optimized thus: the effect of $\mathrm{pH}$ on the sorption process was investigated by varying the $\mathrm{pH}$ of the initial $\mathrm{CU}$ (II) solution between $\mathrm{pH} 3$ 12; the effect of the adsorbent dose was studied at different dosage of $0.2,0.4,0.6,0.8$ and $1.0 \mathrm{~g}$ of the sorbents in contact with fixed CU (II) solution of $500 \mathrm{mg} / \mathrm{L}$. The mixture in the flask was shaken at $200 \mathrm{rpm}$ for $2 \mathrm{~h}$ and the equilibrium concentration of the residual CU (II) was determined spectrophotometrically. The CU (II) sorption kinetic parameters, was studied using a range of CU (II) concentrations [25 to $300 \mathrm{mg} / \mathrm{l}$ ]. A typical experimental procedure was conducted by measuring accurately a liter of the CU (II) solution of known concentration, $2 \mathrm{~g}$ of MMOL was added and agitated [at $200 \mathrm{rpm}$ ] for $240 \mathrm{~min}$, Samples were withdrawn, at fixed time intervals, centrifuged, and the supernatant was analyzed for residual CU (II)using flame atomic absorption spectrophotometer. The amount of CU (II) sorbed per unit mass of the MMOL [q in $\mathrm{mg} / \mathrm{g}$ ] was calculated using the mass balance procedure.

\section{Results and Discursion}

\subsection{Sorbent Characterization}

The modification of MOL produced a material whose PZC value (6.20) was greater than that of the UMOL (3.70). The results of the specific surface area of the UMOL and MMOL showed that the acid treated samplehad higher specific surface area $\left(106 \mathrm{~m}^{2} / \mathrm{g}\right)$ than that of the UMOL $\left(33 \mathrm{~m}^{2} / \mathrm{g}\right)$. The higher specific surface area of the MMOL could be ascribed to the acid modification of the MOL which opened up the pores.

\subsection{Equilibrium Isotherm Studies}

The equilibrium concentration between the CU (11) ions in the fluid phase and the $\mathrm{CU}$ (11) ions in the MMOL at given temperature was studied and the isotherm parameters obtained by using thelinearized models of Langmuir and Freundlich isotherm are presentedin Table 1.

$$
\text { Langmuir: } \frac{C_{e}}{q_{e}}=\frac{1}{K q_{m}}+\frac{1}{q_{m}} C_{e} .
$$

$$
\text { Freundlich }: \log q_{e}=\log K_{f}+\frac{1}{n} \log C_{e}
$$

The values of the monolayer sorption capacities, $\mathrm{q}_{\mathrm{m}}$ $(\mathrm{mg} / \mathrm{g})$, obtained from Langmuir plot of Ce/qe vs Ce is 78.45 $\mathrm{mg} / \mathrm{g}$ while the magnitude of Langmuir constant, $\mathrm{K}_{\mathrm{L}}$, which is the sorption equilibrium constant $\left(\mathrm{dm}^{3} / \mathrm{mg}\right)$ is 1.4642 . The higher the magnitude of the heat of sorption, the stronger the bond formed between the sorbate and the sorbent. The Freundlich constant $\mathrm{k}_{\mathrm{f}}$ and $\mathrm{n}$ which are related to adsorption capacity and sorption intensity respectively, are obtainable from the plots of $\log q \mathrm{e} v s \log c$. The values of this constants are presented in Table 1 . The value of $1 / n$, which is less than unity (0.9463), shows the favorable nature of adsorption of CU (11) on MMOL. The description of the sorption of CU (II) on MMOL by the Freundlich isotherm equations is an indication of the heterogeneity of the surface with a non-uniform distribution of heat of adsorption over the surface of the MMOL. The linear coefficient of determinations, $r^{2}$, was used to evaluate the fitness of each isotherm equation to the experimental data obtained from the optimization process employed.

Table 1. Equilibrium Isotherm Parameters of sorption of CU (II) on MMOL.

\begin{tabular}{llllll}
\hline \multicolumn{2}{l}{ Langmuir isotherm parameter } & \multicolumn{3}{l}{ Freundlich isotherm parameter } \\
\hline $\mathbf{q m}(\mathbf{m g} / \mathbf{g})$ & $\mathbf{K}_{\mathbf{L}}$ & $\mathbf{r}^{2}$ & $\mathbf{K}_{\mathbf{f}}(\mathbf{1} / \mathbf{g})$ & $\mathbf{1} / \mathbf{n}$ & $\mathbf{r}^{2}$ \\
\hline 78.45 & 1.4642 & 0.996 & 53.44 & 0.9463 & 0.998 \\
\hline
\end{tabular}

The values of $r^{2}$ obtained when the experimental data were fitted into Langmuir isotherm equationwas lower than that of Freundlich isotherm equation. The description of the sorption of CU (II) on MMOL by the Freundlich isotherm equations is an indication of the heterogeneity of the surface with a nonuniform distribution of heat of adsorption over the surface of the MMOL. The results of the comparison of the Langmuir sorption capacity $\left(\mathrm{q}_{\mathrm{m}}\right)$ obtained from the present study with the values obtained by other researchers from the use of other sorbents for the removal of CU (II) ions from aqueous solution is presented in Table 2. The result indicated that MMOL compared favorably with the other adsorbents that have been used and the Langmuir sorption capacity was higher than some of the other adsorbents.

Table 2. Comparison of the Lagmuir sorption capacity (qm in $\mathrm{mg} / \mathrm{g}$ ) of different sorbents forCU (II).

\begin{tabular}{lll}
\hline ADSORBENTS & qm(mg/g) & References \\
\hline Modified silica aerogel & 90.1 & {$[16]$} \\
Amino functionalized $\mathrm{Fe}_{3} \mathrm{O}_{4} @ \mathrm{SiO}_{2}$ core- & 29.85 & {$[17]$} \\
shell NPsCross linked chitosan with & & \\
Epichlorohydrin & 35.46 & {$[18]$} \\
a loofa sponge (FBILS) & 98.9 & {$[19]$} \\
Modified moringaoleifera leaves & 78.45 & [This work] \\
\hline
\end{tabular}

\subsection{Sorption Kinetics Studies}

The initial CU (II) ions concentration was studied to observe if the initial concentration of CU (II) ions would have an influence on the sorption process. In the range of $\mathrm{CU}$ (II) ions concentration studied, the uptake of the CU (II) was 
rapid in the first $50 \mathrm{~min}$. The rapid uptake then gave way to a much slower adsorption after 50 mins (Figure 2). This initial rapid uptake can be attributed to the concentration gradient created at the start of the adsorption process between solute concentration in solution and that of the MMOL surface. As the CU (II) loading increases this gradient reduces and gives way to slower uptake and there is no change in adsorption on further increase in contact time.

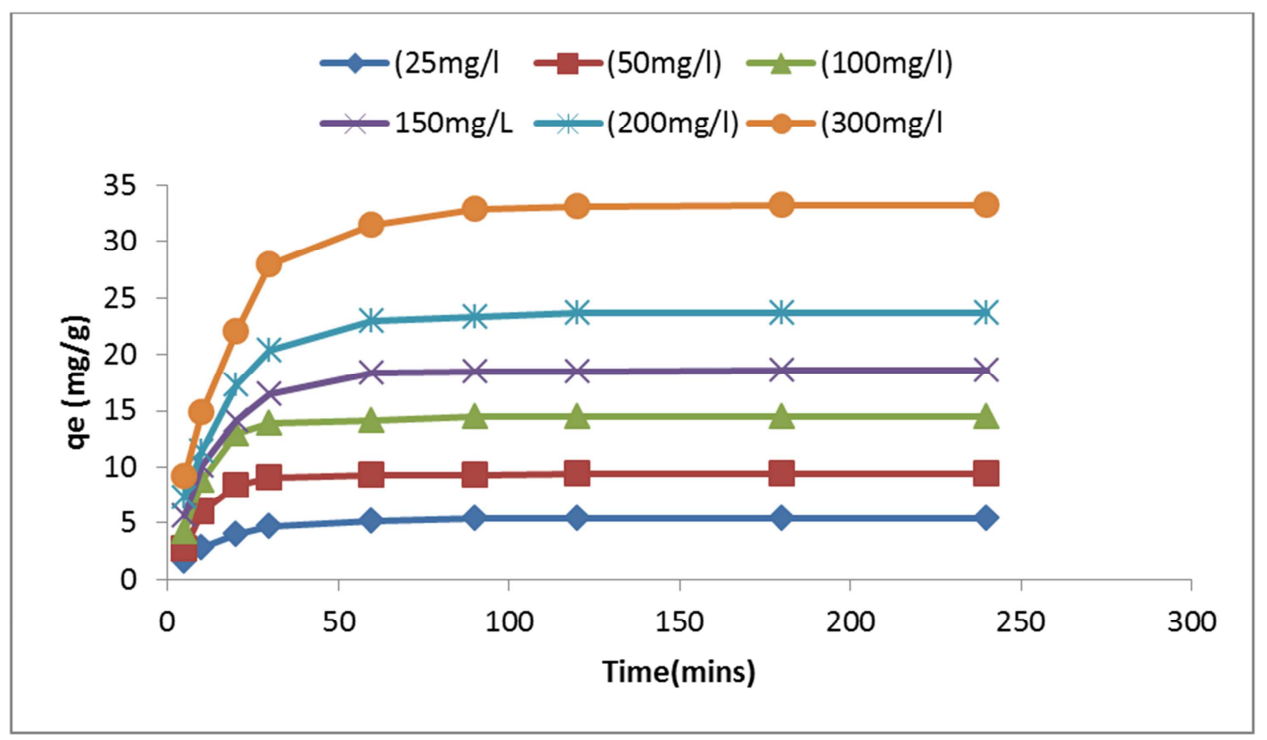

Figure 2. Effect of initial CU (II)concentration ( $\mathrm{mg} / \mathrm{l})$ and time on the sorption ofCU(II) by MMOL.

In order to study the mechanism of sorption and potential rate determining steps, pseudo first and second order kinetic models was used to test the experimental data obtained from the variability of the initial CU (II) ions concentration. pseudo first-order equation 4, and pseudo second-order equation 5, were tested with the data obtained from the kinetic studies, thus:

$$
\begin{gathered}
\log [\mathrm{qe}-\mathrm{qt}]=\log [\mathrm{q}]-[\mathrm{k} / 2.303] \mathrm{t} \\
\mathrm{t} / \mathrm{qt}=1 / \mathrm{kqt}+1 / \mathrm{qt}
\end{gathered}
$$

The plots obtained for these kinetic models are presented in Figure 3 and Figure 4 respectively.

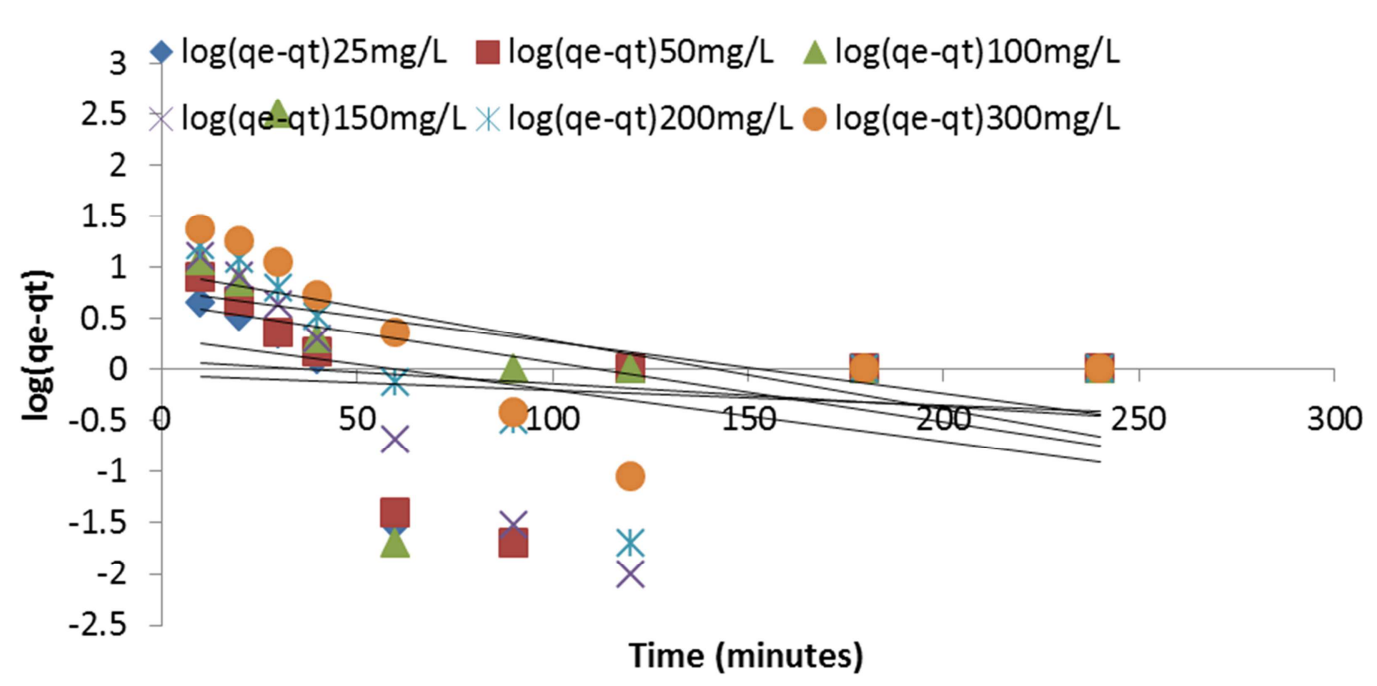

Figure 3. Pseudo-first-order kinetic plots for the removal of CU(II) by MMOL at different initial CU(II) concentration. 


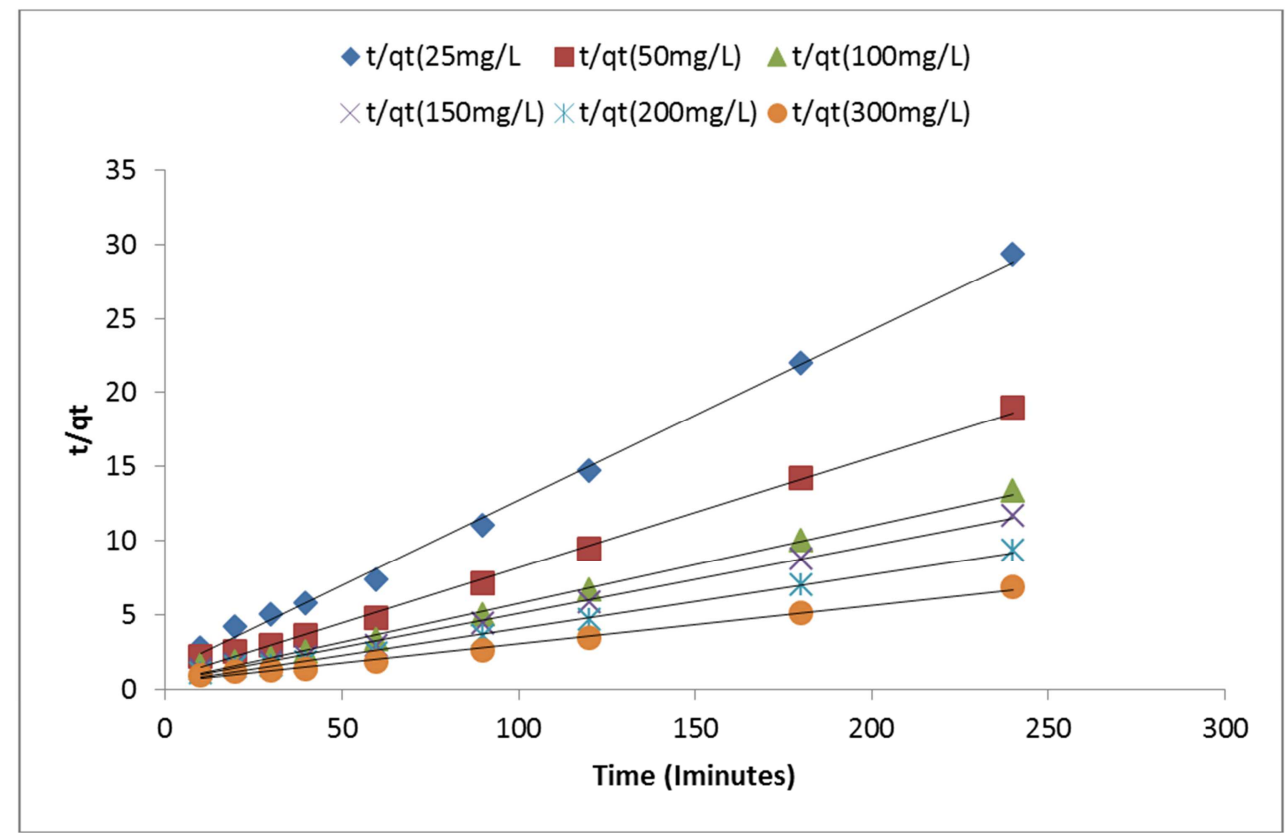

Figure 4. Pseudo- second-order kinetic plots for the removal of CU(II) ions by MMOL atdifferent initial CU (II) concentration.

The results from the analysis of the data obtained from these plots are presented in Tables 3 . The experimental data showed better fitting to pseudo second order (r2=0.993 - 0.997).

Table 3. Kinetic Parameters of CU (II) Sorption on MMOL.

\begin{tabular}{lllllll}
\hline Initial Conc. & Pseudo first order & & & \multicolumn{2}{l}{ Pseudo second order } \\
\hline $\mathbf{M g} / \mathbf{L}$ & $\mathbf{q}_{\mathbf{e} 1}$ & $\mathbf{K}_{\mathbf{1}}$ & $\mathbf{r}^{2}$ & $\mathbf{q e}_{\mathbf{2}}$ & $\mathbf{K}_{\mathbf{2}}$ & $\mathbf{r}^{\mathbf{2}}$ \\
\hline 25 & $2.3 \times 10^{-3}$ & $3.6 \times 10^{-3}$ & 0.018 & 8.6956 & 0.0932 & 0.997 \\
50 & $4.6 \times 10^{-3}$ & $4.3 \times 10^{-3}$ & 0.039 & 13.5135 & 0.0864 & 0.996 \\
100 & $11.5 \times 10^{-3}$ & $5.9 \times 10^{-3}$ & 0.127 & 19.2308 & 0.0611 & 0.995 \\
150 & $11.5 \times 10^{-3}$ & $10.5 \times 10^{-3}$ & 0.136 & 22.2222 & 0.0583 & 0.996 \\
200 & $11.5 \times 10^{-3}$ & $12.8 \times 10^{-3}$ & 0.261 & 27.7778 & 0.0579 & 0.995 \\
300 & $13.8 \times 10^{-3}$ & $15.4 \times 10^{-3}$ & 0.419 & 40.000 & 0.0567 & 0.993 \\
\hline
\end{tabular}

This is a pointer to the fact that the sorption of the CU(II) ions moieties on MMOL occurred via chemisorptions. If the sorbate uptake is chemically rate controlled, then the pseudo second order constants will be independent of particle diameter and flow rate will depend on concentration of the ions in solution [20]. A review of the results, presented in Tables 3, showed that the pseudo second order parameters obtained from the uptake of CU(II) ions onto MMOL (qe and $\mathrm{k}_{2}$ values) varied with the initial CU (II) concentration.

\subsection{Effect of Adsorbent Dosage}

The effect of the adsobent dose on the sorption of copper (II) from aqueous solution onto MMOL was carried out. The result showed that the sorptions of CU (11) are functions of MMOL dosage. Increasing the dosage of the MMOL and keeping the CU(11)concentration constant makes a large number of sites available for a fixed concentration of sorbate. This is anticipated because an increase in MMOL dosage will lead to an increase in the quantity of sorption sites available for sorbent-sorbate interaction [21]. Meanwhile a reverse trend was observed in the loading capacity $(\mathrm{q} t)$ when the linear form of Langmuir equation was used to analyzed the isotherm experiments and the results obtained are presented in Table 4.

Table 4. Effect MMOL dosage on the sorption of CU(II).

\begin{tabular}{llll}
\hline Sorbent dose & $\mathbf{q m}$ & $\mathbf{K}_{\mathbf{L}}(\mathbf{m g} \mathbf{g} \mathbf{g})$ & $\mathbf{r}^{2}$ \\
\hline 0.2 & 78.45 & 1.4642 & 0.998 \\
0.4 & 65.39 & 1.6745 & 0.993 \\
0.6 & 61.72 & 1.7231 & 0.985 \\
0.8 & 53.82 & 1.9367 & 0.987 \\
1.0 & 38.66 & 1.9876 & 0.988 \\
\hline
\end{tabular}

The results showed that as the MMOL dose was increased from 0.2 to $1.0 \mathrm{~g} / \mathrm{L}$, a reduction was observed in the values of the monolayer sorption capacities, qm, from 78.73 to 38.66 $\mathrm{mg} / \mathrm{g}$. The reduction in the sorbent capacity with increase in dose could be attributed to two reasons: the increase in sorbent dose at constant $\mathrm{CU}$ [11] ions concentration and volume will lead to unsaturation of sorption sites through the sorption process [22-24] and secondly may be due to particulates interactions. Such aggregation would lead to a decrease in total surface area of the sorbent and an increase in diffussional path length [22]. The value of the sorption equilibrium constant, $\mathrm{K}_{\mathrm{L}}$, increased with increase in the sorbent dose. 


\subsection{Effect of $\mathrm{pH}$}

The $\mathrm{pH}$ of the medium of interaction between the sorbent and the sorbate is an important parameter in any adsorption process. This dependence is closely related to the acid-base properties of various functional groups on the adsorbent surfaces [25]. The change of $\mathrm{pH}$ affects the adsorptive processes via the dissociation of functional groups on the active sites of the adsorbent. This subsequently leads to a shift in the reaction kinetics and equilibrium characteristics of the adsorption process [26]. An increase in metal adsorption with increasing $\mathrm{pH}$ values can be explained on the basis of competition between the proton and metal ions for the same functional groups, and a decrease in the positive surfacecharge, which results in a higher electrostatic attraction between the biosorbent surface and the metal [27]. Low $\mathrm{pH}$ conditions allow hydrogen and hydronium ions to compete with metal binding sites on the biomass, leading to poor uptake. Biomasses are materials with an amphoteric character; thus, depending on the $\mathrm{pH}$ of the solution, their surfaces can be positively or negatively charged. At $\mathrm{pH}$ values greater than the point of zero charge $(p H>P Z C)$, the biomass surface becomes negatively charged, favoring the adsorption of cationic species. However, adsorption of anionic species will be favored at $\mathrm{pH}<p H p z c$. The $p H_{p z c}$ of the MMOL is between 6.0 and 6.2, indicating that the surface of the biosorbent presents acid characteristics. The surface charge of the MMOL is positive at $\mathrm{pH}<\mathrm{PZC}$, is neutral at $\mathrm{pH}$ $=\mathrm{PZC}$ and is negative at $\mathrm{pH}>\mathrm{PZC}$.

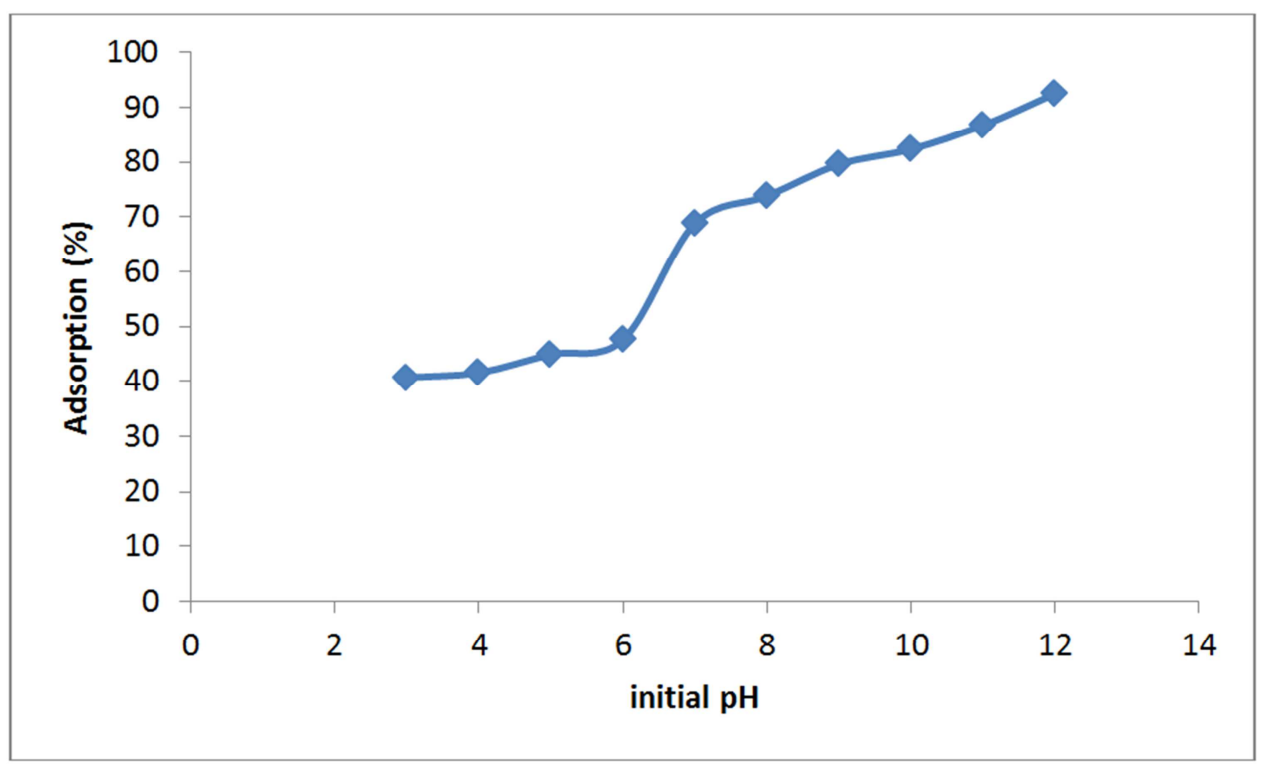

Figure 5. Effect of $p H$ on the sorption of $C U$ (II) ions ontoMMOL.

\section{Conclution}

The capacity of MMOL to remove CU(II) ions from aqueous solution was investigated using equilibrium isotherm analysis. Langmuir and Freundlich isotherm equations were used to describe the sorption process. Freundlich isotherm equations had the best correlations amongst the two isotherm equations used. This shows the heterogeneity of the surface of the MMOL and the multilayer adsorption nature of the $\mathrm{CU}(\mathrm{II})$ ions on MMOL. The effect of initial CU(II) ions concentration and MMOL dosage on the sorption dynamics of CU (II) on MMOL was studied. The experimental data obtained from the studies were fitted to pseudo first and pseudo second order kinetic models and the results showed an extremely high coefficient of determination $\left(r^{2}\right)$ when it was fitted to the pseudo second order kinetic models. Also increase in the MMOL dose at fixed CU (II) concentration caused a reduction in the amount of CU (II) ions sorbed due to an increase in the large number of sites that are ready for CU (II) adsorption. Moreso, CU(II) ions solution $\mathrm{pH}$ must be optimally selected to obtain the highest possible removal of
CU (II) ion. As shown by the results, CU (II) sorption onto MMOL increases with increase in $\mathrm{pH}$ of the $\mathrm{CU}$ (II) solution.

\section{References}

[1] S. Naser., A. Reza, \& K. Bakhtiar, Removal of Copper ions from aqueous solutions Usingpolymer derivations of poly (styrene-altmaleic anhydride). Egyptian Journal of Petroleum. 2017, 26, 375-389.

[2] M. Bilal, J. A. Shah, T. Ashfaq, S. M. H. Gardazi, A. A. Tahir, A. Pervez, H. Haroon \& Q. Mahmood, (2013) "Waste biomass adsorbents for copper removal from industrialwastewater-A review," Journal of Hazardous Materials, 2013, vol. 263, pp. 322-333.

[3] O. Demirbaş, A. Karadağ, M. Alkan.\& M. Doğan, M. (2008) "Removal of copper ionsfrom aqueous solutions by hazelnut shell," Journal of Hazardous Material S, 2008, vol. 153, pp. 677-684,

[4] M. Dinesh \& P. S. Kunwar (2002):Single- and multicomponent adsorption of cadmiumand zinc usingactivated carbon derived from bagasse - an agricultural waste $\$$ Water Research, 2002, 36, 2304-2318. 
[5] L. I. Xiaomin, T. Yanru, C. Xiuju, L. Dandan, L. Fang \&S. Wenjing S. Colloids and Surfaces, 2008, 317, 512-521.

[6] Y. W. Fa, H. Wang \& J. Wei Ma, Adsorption of cadmium (II) ions from aqueoussolutionby a new low-cost adsorbentBamboo charcoal, Journal of Hazardous Materials, 2010, 177, 300-306.

[7] F. Anwar, S. Latif., M. Ashraf \& A. H. Gilani, "Moringaoleifera: a food plant with multiplemedicinal uses," Phytotherapy Research, 2007, vol. 21, pp. 17-25,

[8] V. Jahn, H. A. Musnad \& H. Burgstaller, "Tree that purifies water: Cultivating multipurposeMoringaceae in the Sudan," Unasylva. 1986.

[9] V. Nand, M. Maata, K. Koshy \& S. Sotheeswaran, "Water Purification using MoringaoleiferaandOtherLocallyAvailable Seeds in Fiji for Heavy Metal Removal," InternationalJournal of Applied Science andTechnology, 2012, vol. 2, pp. 125-129.

[10] M. Suarez, J. J. Entenza, J. J. Doerries, J. Meyer, L. Bourquin, J. Sutherland, L. Marison, P. Moreillon\& N. Mermod"Expression of a plant-derived peptide harboringwater-cleaning and antimicrobial activities,"Biotechnology and Bioengineering, 2003, vol. 81, pp. 13-20. http://dx.doi.org/10.1002/bit.10550

[11] V. N. Alves \& N. M. M. Coelho "Selective extraction and preconcentration of chromiumusingMoringaoleiferahusks as biosorbent and flame atomic absorption spectrometr," Microchemical Journal, 2013, vol. 109, pp. 16-22.

[12] F. N. Obuseng, \& H. M. Kwaambwa., "A study of the removal of heavy metals fromaqueous solutions by Moringaoleiferaseeds and amine-based ligand 1, 4-bis [N, Nbis(2-picoyl)amino]butane," Analytica ChimicaActa, 2012, vol. 730, pp. 87-92.

[13] R. A. Ongulu, J. L. Kituyi \& Z. M. Getenga, Biosorption of $\mathrm{Pb}^{2+}$ and $\mathrm{Cr}^{2+}$ Using MoringaOleiferaand their Adsorption Isotherms Science Journal of Analytical Chemistry, 2015, 3(6): 100-108.

[14] G. Sears, Determination of specific surface area of colloidal silica by titration with sodium hydroxide. Analytical Chemistry, 1956, 28, 1981-1983.

[15] L. S. Balistrieri, \& J. W. Murray, The surface chemistry of goethite $(\alpha-\mathrm{FeOOH})$ in major ionseawater. Am. J. Sci., 1981, 281 (6), 788- 806.
[16] H. R. Pouretedal \& M. Kazemi, sodium silicate precursor and its application as adsorbentof $\mathrm{Cu}^{2+}, \mathrm{Cd}^{2+}$, and $\mathrm{Pb}^{2+}$ ions. International Journal of Industrial Chemistry, 2012, 3: 20-28.

[17] J. Wang, S. Zheng, Y. Shao, J. Liu \& Z. Xu, core- shell magnetic nanomaterial as a novel adsorbent for aqueous heavy metals removal. Journal of Colloid Interface Science, 2010, 349: 293-299.

[18] A. H. Chen, S. C. Liu, \& C. Y. Chen, Comparative adsorption of $\mathrm{Cu}(\mathrm{II}), \mathrm{Zn}(\mathrm{II})$, and $\mathrm{Pb}$ (II) ions in aqueous solution on the cross linked chitosan with epichlorohydrin. Journal Hazard Mater, 2008, 154: 184-191.

[19] M. Iqbal\&R. G. J. Edyvean, Biosorption of lead, copper and zinc in a loofa sponge immobilised biomass of Phanerochaetechrysosporium. Min EngInt, 2004, 17: 217-223.

[20] N. A. Oladoja, C. O. Aboluwoye, I. A. Ololade, O. L. Adebayo, S. E. Olaseni, \&AdelagunR. O. A.: Intercalation of gastropod shell derived calcium oxide in clay andapplication in phosphate abstraction from aqua medium. Industrial and Engineering Chemistry research, 2012, 51 (45), 1463714645 .

[21] K. V. Kumar, V. Ramamurthi,\&S. Sivanesan, "Modeling the Mechanism InvolvedDuringthe Sorption of Methylene Blue onto Fly Ash". Journal of Colloid Interface Science., 2006, 1; $284,14-21$.

[22] R. P Han., Y. F. Wang, P. Han, J. Shi, J. Yang, Y. S. Lu., JournalHazard. Mater., 2006, 133(1-3), 262-268.

[23] A. Shukla, Y. H. Zheng, P. Dubey, J. L. Margrare., S. S. Shukla, J. of Hazard Mater. 2002 95(1-2), 137.

[24] L. J. Yu, S. S. Shukla, K. L. Doris, A. Shukla, J. L. Masgrave, J. of Hazard. Mater, 2003, 100(1-3), 53.

[25] G. M. Pereira, M. A. Z. Arruda. Trends in preconcentration procedures for metaldetermination using atomic spectrometry techniques. MicrochimicaActa, 2003; 141, 115-31.

[26] I. D. Mall, V. C. Srivastava, N. K. Agarwal, Removal of orange $\mathrm{G}$ and Methyl violet dyes byadsorption onto bagasse fly ash-Kinetic study and equilibrium Is other manalyses. Of Dyes Pigments, 2006, 69, 210-223.

[27] S. Senthilkumaar, S. Bharathi, D. Nithyanandhi, V. Subburam, Biosorption of toxic heavymetals from aqueous solutions. Bioresource Technology 2000; 75 163-5. 